\title{
A História das Idélas Segundo Michel Foucault e Quentin Skinner
}

\author{
Marcos Antônio Lopes ${ }^{1}$
}

A sagacidade dos críticos não se enganou: de uma análise como a que empreendo, as palavras estão tão deliberadamente ausentes quanto as próprias coisas; não há nem descrição de um vocabulário nem recursos à plenitude viva da experiência; [...] fica-se, tenta-se ficar no nível do próprio discurso. ${ }^{2}$

MICHEL FOUCAULT

Tem sido freqüentemente argumentado que 0 critério final de correção na interpretação apenas pode ser alcançado estudando-se 0 contexto original no qual um trabalho foi escrito. [...] Antes de mais nada, eu tenho tentado argumentar que, no trabalho de se capacitar para interpretar o sentido de um texto, é necessário levarse em conta outros fatores, além do próprio texto. ${ }^{3}$

QUENTIN SKINNER

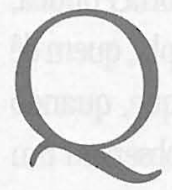

uando surgiu nos finais dos anos 1960 como um campo teórico dotado dos elementos que compunham uma nova teoria interpretativa do discurso político, o contextualismo lingüístico deu origem a um debate ainda em aberto. Em sua origem, esta corrente atacou algumas das teorias hegemônicas no cenário intelectual daqueles anos, abalando convicções e disseminando dúvidas. No alvo central de sua crítica estavam a carência de historicidade e o pragmatismo imediatista predominantes na Teoria Política. Historiadores da Teoria Política como Quentin Skinner e John Dunn, autores dos

1 Doutor em História pela USP. Professor do Depto. de Ciências Sociais da Universidade Estadual de Londrina. Autor de Para ler os clássicos do pensamento político: um guia bistoriográfico (Editora FGV), Voltaire político (Editora Unesp), Voltaire bistoriador (Papirus), Voltaire literário (Imaginário), o político na modernidade (Loyola), 0 absolutismo (Brasiliense), A imagem da realeza (Ática), dentre outros títulos sobre as relações entre os intelectuais e o poder político.

2 Foucault, M. A arqueologia do saber. Rio de Janeiro: Forense Universitária, 2002. p. 55.

3 Skinner, Q. "Motives, Intentions and the explanation of social action". In: Tulux, J. Meaning and Context. Quentin Skinner and bis critics. Cambridge: Polity Press/Basil Blackwell, 1988. pp. 76-78. 
primeiros e mais enérgicos ensaios teóricos em defesa de um novo programa de pesquisa, esgrimiram contra uma História do Pensamento Político que, nos tempos da Guerra Fria, estava interessada em explorar aspectos a-históricos, num mundo ainda aturdido pela presença ameaçadora dos regimes totalitários. 0 mundo mudou, o Estados totalitários ruíram, e a história efetiva se encarregou de alterar o foco das discussões. Em fins dos anos 1970, e ao longo da década seguinte, o debate teórico acabou por adquirir novos contornos e ganhou complexidade, tanto pelo fortalecimento do contextualismo lingüístico como teoria interpretativa de textos políticos quanto pela entrada em cena de outros interlocutores, o que acabou por resultar em atitudes imperialistas de todas as partes envolvidas.

Em artigo intitulado "Razões da Filosofia Política", que integra o livro de ensaios Teoria Geral da Política, Norberto Bobbio examina o clima de tensão existente em alguns campos limítrofes das ciências humanas. Nesse artigo Bobbio afirma: "As nem sempre boas relações, para não dizer a desconfiança recíproca, entre historiadores das doutrinas políticas e filósofos da política são efeito de incompreensíveis (perdoem o trocadilho) incompreensões, quando não de completos mal-entendidos". ${ }^{4}$ Há nesta ironia conteúdo para um vastíssimo campo de reflexão. Este texto pretende discutir aspectos teóricos que demonstram algumas das referidas incompreensíveis incompreensões. 0 que nos ocupa neste artigo é a tentativa de sintetizar alguns traços centrais no pensamento histórico de Quentin Skinner e de Michel Foucault, naquilo que se refere às teorias de interpretação de textos. No que diz respeito às perspectivas de análises em Teoria Política, os métodos de abordagens dos textos são muito diversificados. Há, por exemplo, quem dê valor apenas às questões candentes do tempo presente, perspectiva esta que, quando radicalizada, não deixa de revelar um grau acentuado de miopia. Como observou um cientista político norte-americano,

A História não tem importância — eis a atitude de muitos cientistas políticos. [...] essa atitude pode ser explicada pelo fato de que as pesquisas em ciência política envolvem, preponderantemente, estudos sobre eventos e instituições contemporâneos. [...] Com efeito, os historiadores escreveram muito pouco sobre os acontecimentos que tiveram lugar depois do fim da II Guerra Mundial, o principal campo de pesquisas para a grande maioria dos cientistas políticos. [...] Sem dúvida, muito da

Boвbio, N. Teoria Geral da Política: a Filosofia Política e as Lições dos Clássicos. Rio de Janeiro: Campus, 2000. p. 95. 
A Histórla das Idélas Segundo Michel Foucalt e Quentin S <ininer • 85

atração da Idade Média ou das colônias americanas para os historiadores reside no fato de que a maioria, se não todas as consequiências desses acontecimentos, já se manifestou e pode ser usada como base de avaliação.

E é neste ponto que surgem diversas dúvidas, como as expostas por John Horton, acerca da forma "mais adequada" e da real importância de se estudar os chamados textos clássicos da Teoria Política. Seria preciso estudá-los por uma perspectiva a princípio histórica, empregando os métodos e práticas do historiador para reconstruir o significado histórico dos textos? Ou dever-se-ia focá-los por um prisma filosófico como obras que pretendem oferecer verdades gerais acerca da natureza da vida e da organização política com vistas a avaliar a força de seus argumentos, a revelação de suas suposições e coisas do gênero? ${ }^{6} \mathrm{Na}$ concepção de alguns destacados historiadores do pensamento político, a Teoria Política pode ser adequadamente estudada lançando-se mão do método histórico. Mesmo especialistas de relevo na cena da Teoria Política, como Leo Strauss, que tomam o "partido da intemporalidade" das idéias dos grandes pensadores, reconhecem a necessidade do emprego de uma abordagem histórica dos textos políticos. ${ }^{7}$ Mas, mesmo quando se tenta dividir este problema em partes, para oferecer uma resposta mais ordenada e rigorosa, a tendência é a de elevar a complexidade do debate teórico. Isto porque não há nem a mais remota possibilidade de consenso sobre o que é ou deve ser o referido método histórico no estudo da Teoria Política e em quais operações intelectuais ele consiste. Ora, há quase tantos métodos históricos para a análise do discurso político quanto há historiadores.

Para Skinner, a Teoria Política deve ocupar-se com a reconstituição do sentido histórico das idéias. Trata-se de descobrir o que os pensadores políticos pretenderam dizer em seus textos. Para tanto, é necessário recuperar as intenções de tais autores a partir da análise do contexto histórico de produção de suas obras, levando-se em linha de

Jensen, R. A História e o Cientista Político. In: Lipset, S. Política e Ciências Sociais. Rio de Janeiro: Zahar, 1972. p. 48 s.

6 Cf. Horton, J. La filosofía política y la política. In: LeFrwich, A. (org.). Qué es la política? México: Fondo de Cultura Económica, 1992. p. 201.

7 "I assumed that political philosophy, as an essentially non-historical pursuit, is today in need of a critical study of its history; that such a critical history pressuposes that one understand the great thinkers of the past as they understood themselves; that the history of political philosophy requires an adequate division into periods; an that only such a division can be considered adequate as corresponds to the self-consciouness of the actors, i.e of great political philosophers". Strauss, L. The Political Pbilosophy of Hobbes. Its Basis and Its Genesis. Chicago: The University of Chicago Press, 1984. p. XV. 
consideração os eventos e os debates travados com as questões políticas formuladas em seu próprio tempo por outros pensadores. Assim, o texto assume a dimensão de uma resposta consciente, uma dimensão de ato lingüístico, que revela seu sentido político quando focado em contraste com asua própriaépoca. Na perspectiva do contextualismo lingüístico, John Pocock afirma que "Uma grande parte de nossa prática como historiadores consiste em aprender a ler e reconhecer os diversos idiomas do discurso político da forma pela qual se encontravam disponíveis na cultura e na época em que o historiador está estudando: identificá-los à medida que aparecem na textura lingüística de um determinado texto e saber o que eles comumente teriam tornado possível ao autor do texto propor ou 'dizer"' 8

Esse 'método' revela seu rigor na medida em que requer um conhecimento apurado das convenções lingüísticas que permearam os debates políticos do passado. ${ }^{9}$ Assim, não basta ler e interpretar as passagens mais complexas dos textos clássicos da Filosofia Política. É preciso ir além, porque é necessário que o historiador se familiarize com o sentido histórico das palavras e, por conseguinte, com o sentido histórico das idéias. Para tanto, ele deve elaborar um questionário inicial que poderia partir de indagações como: o que tais idéias significavam no tempo em que foram concebidas, por que foram concebidas, de que forma foram utilizadas e que tipo de resultado efetivo pretendiam alcançar? Ora, a experiência da leitura demonstra que as idéias não se separam da linguagem. É sempre por um processo de incorporação da escrita do outro que se ganha o poder de pensar o que ele mesmo busca pensar. Apesar das inúmeras limitações dos métodos de análise e de interpretação, a compreensão dos textos do passado é uma operação intelectual possivel. Para tentar reconstituir o sentido de um texto políitico precisamos contrastá-lo com o contexto histórico em que foi produzido, procurando obter informações detalhadas acerca do grupo social do autor, a conjuntura em que escreveu sua obra, seus interesses intelectuais, seus engajamentos políticos, etc. Esse inventário de problemas historiográficos, esse questionário de dúvidas e de incertezas, da forma como aparece nos textos de Skinner, resume-se à seguinte indagação: o que Maquiavel, Hobbes ou, de uma maneira geral, qualquer outro pensador político "estavam fazendo" quando escreviam?

8 Pocock, J.G.A. Linguagens do ideário político. São Paulo: Edusp, 2003. p. 33.

9 Para uma análise profunda da metodologia de Pocock e Skinner confira a avaliação de Bobbio 2000: 94ss. Para a exposição do chamado "método" do contextualismo lingüístico do círculo de Cambridge consulte-se o capítulo introdutório de Pocock "0 estado da arte", em Linguagens do ideário político, bem como as introduções teórico-metodológicas dos vários livros de Quentin Skinner publicados no Brasil, notadamente As fundações do pensamento político. São Paulo: Companhia das Letras, 1996; Razão e retórica na filosofia de Hobbes e Liberdade antes do liberalismo, (ambos publicados em 1999 pela Editora Unesp). Veja também: HARIsw, D. "Intellectual History and the return of literature. In: American Historical Review. 94 (1989). pp. 581609; Lopes, M.A. Para ler os clássicos do pensamento político. Rio de Janeiro: Editora FGV, 2002. 
0 contextualismo lingüístico foi responsável por um sensível avanço no plano de uma teoria da interpretação de textos. A História do Pensamento Político, gênero com sólida tradição intelectual que remonta aos finais do século XIX, nos Estados Unidos, e aos inícios do século XX, na Inglaterra, conheceu um notável impulso de renovação a partir de fins dos anos 1960. Alguns textos teóricos escritos nessa época por autores como Skinner e Dunn acabaram por desencadear debates que se polarizaram em torno de novos pressupostos de interpretação de textos. A reconstituição do vocabulário normativo por meio do qual se expressaram autores como Thomas Hobbes e John Locke, segundo os responsáveis pela fundamentação teórica das abordagens contextualistas dos textos políticos, tornaria possível acessar o sentido original de uma obra de pensamento. E isto, sobretudo, pelo esforço intelectual empregado na compreensão das intenções do autor. Por intenções do autor entenda-se não propriamente a compreensão do processo intelectual da criação de um pensamento abstrato, uma operação puramente mental desprovida de fins pragmáticos. 0 propósito seria 0 de compreender os efeitos práticos gerados por este exercício intelectual do autor, ou melhor, que tipo de ação um determinado autor pretendia desencadear a partir de idéias postas em circulação sob a forma de discurso político. Para Skinner, acessar esse propósito seria possível colocando-se um discurso central em contraste com outros discursos, fossem de autoria do próprio autor ou mesmo de seus interlocutores, que com ele estabelecessem relações. As relações intertextuais se configurariam assim como uma ferramenta eficaz no trabalho da interpretação. Confrontando-se um texto com outros, as intenções de um autor ficariam evidentes, ao revelar-se a força ilocucionária do discurso político. Para tanto, seria necessário cotejar documentos pessoais do autor em análise, ou textos de variada autoria, desde que entretecessem relações com a obra-foco da análise. Como se referiu o próprio Skinner, a análise do contexto faz parte de um círculo hermenêutico muito mais vasto que a simples exegese do texto. ${ }^{10}$

A Filosofia da Linguagem, na qual os historiadores de Cambridge se inspiraram, havia denominado os efeitos produzidos pelo discurso como 'atos de fala'. E este foi um dos aspectos que historiadores como Skinner julgaram oportuno incluir em uma teoria interpretativa no campo da História do Pensamento Político. 0 contextualismo lingüístico distinguiria as intenções autorais como ações programáticas, atos do discurso, avaliando os enunciados do texto em relação às reações que o autor teria pretendido desencadear em seu tempo. Está presente nessa perspectiva de análise do discurso político uma teoria da ação, colocada em movimento por personagens históricos movidos por

10 "... the recovery of the historical meaning of any given text is a necessary condition of understending it, and this process can never be achieved simply by studying the text itself". Skinner In: Tully 1988, p. 104. 
interesses e compromissos circunstanciais. "Estas proposições foram enunciadas por indivíduos que pretendiam dizer e fazer coisas ao enunciá-las. Eles estavam engajados em um determinado tipo de atividade lingüística que, por seu turno, era parte de uma atividade social ou política mais geral", esclarece John Gunnel, ao refletir sobre a obra de Skinner, Dunn e Pocock. ${ }^{11}$

Assim é que, constituindo-se o texto político numa 'promessa' de ação, ele aparece como um agente de intervenção orientado por um claro conteúdo prescritivo, não podendo ser dissociado das circunstâncias que o geraram. Está expresso aí todo o conteúdo histórico presente no método contextualista. Desse modo, o sentido original da obra de pensamento poderia vir à tona, saltar aos olhos do intérprete, a partir da identificação do que "o autor estava fazendo" no momento e lugar de produção de sua obra: " 0 que, exatamente, 0 procedimento aqui proposto nos permite identificar nos textos clássicos que não se possa encontrar à sua mera leitura? A resposta, em termos genéricos, penso eu, é que ele nos permite definir o que seus autores estavam fazendo quando os escreveram. Podemos começar assim a ver não apenas quais argumentos eles apresentavam, mas também as questões que formulavam e tentavam responder, e em que medida aceitavam e endossavam, ou contestavam e repeliam, ou às vezes até ignoravam (de forma polêmica), as idéias e convenções então predominantes no debate político". ${ }^{12}$ Para Skinner, o sentido de um texto deve ser apreendido em sua relação com o mundo histórico que lhe propiciou sua forma e seu conteúdo singulares. Se Hobbes tomou Aristóteles ou qualquer outro filósofo como interlocutor, suas reflexões políticas foram direcionadas aos homens de seu tempo. Então, o chamado diálogo de tradições não faz sentido quando se trata de apreender o sentido original de um texto, e não pode ser tomado como a chave da operação interpretativa. 0 contextualismo lingüístico se ocupa, primacialmente, em recuperar 0 sentido das idéias em meio ao processo de sua difusão e possível transformação em sistema doutrinal. Sob esse aspecto, este gênero historiográfico pode ser caracterizado como uma história social das idéias. ${ }^{13}$

Algumas das críticas ao contextualismo lingüístico foram desferidas por teorias da interpretação vinculadas às tendências da hermenêutica ou do pós-estruturalismo, tendo em Paul Ricoeur, Roland Barthes e Jacques Derrida os seus expoentes de maior

11 Gunnel, J. Teoria Política. Brasilia: Editora UnB, 1981. p. 71.

${ }^{12}$ Skinser, Q. As fundações do pensamento político. São Paulo: Companhia das Letras, 1996. p. 10.

${ }^{13}$ Apresentações ao mesmo tempo críticas e panorâmicas acerca do contextualismo lingüístico encontram-se em dois livros acessíveis ao leitor brasileiro: Pocock, J.G.A. Linguagens do ideário político. São Paulo: Edusp, 2003 e Gunnel, J. 1981, Op.cit. 
visibilidade. ${ }^{14}$ Tais autores indagavam quais formas de abordagem tornariam possível estabelecer qualquer espécie de contato com uma mente situada por vezes num ponto muito remoto do passado. Concluindo pela impossibilidade de um tal projeto, esses teóricos só podiam admitir que o acesso às intenções de um autor perdido nas profundezas do tempo era algo tão difícil como atravessar uma montanha, sem transpô-la por cima ou contorná-la pelas laterais. No plano da história das idéias, Michel Foucault desenvolveu com muita clareza e força de expressão a lógica dessa forma de interpretar os textos: " 0 s enunciados devem aí ser tratados em massa e segundo o que têm em comum; sua singularidade de acontecimento pode ser neutralizada; perdem importância também a identidade de seu autor, o momento e o lugar de seu aparecimento". ${ }^{15}$

A visada pós-estruturalista não vai se interessar pelos acontecimentos gerados por agentes históricos. Trata-se de um modelo de "leitura interna que considera um texto nele mesmo e por ele mesmo, que o constitui como auto-suficiente e procura nele mesmo sua verdade, fazendo abstração de tudo o que está ao redor" ${ }^{16}$ Não que Foucault negasse a história efetiva como ocorrência real, concreta; mas, para ele, acontecimentos não falam por si mesmos. Isto pode ser ilustrado com um episódio que, desde os finais do século XVIII, cindiu ao meio a história da França: a Revolução Francesa. Para Foucault, nada há de muito relevante em examinar as suas fases e as implicações contextuais, por exemplo, do Período Jacobino, da Reação Termidoriana, etc. A relevância representada pela evidência histórica de que a Revolução é a Revolução está no 'fato' de que ela deve ser focada como uma luta pelo controle do discurso político entre facções que cerram fileiras em torno dos valores ideológicos que o evento fez emergir; luta esta que, diga-se de passagem, nunca cessou de existir. Portanto, nada mais relevante do que as práticas discursivas geradas por este evento. É assim que o método interpretativo do autor de $A$ arqueologia do saber ocupa-se, sincrônica e diacronicamente, com as "camadas ininterruptas de efeitos" produzidos pelo pensamento, sempre procurando ressaltar "a regularidade de uma prática discursiva que é exercida, do mesmo modo, por todos os seus sucessores menos originais, ou por alguns de seus predecessores". ${ }^{17}$

Foucault quis demonstrar, na esteira de Nietzsche, que as interpretações derivadas dos acontecimentos sempre serão mais relevantes do que os próprios fatos. Se os

${ }^{14}$ Cf. Darnton, R. O beijo de Lamourette. São Paulo: Companhia das Letras, 1995. p. 166.

${ }^{15}$ Foucault, M. Op. cit.p. 161 s.

${ }^{16}$ Bourdieu, P. “A leitura: uma prática cultural”. In: Chartier, R. (Org.). Op. cit. p. 233.

17 Foucautr, M. Op. cit. p. 165. Como afirma Foucault acerca da noção de temporalidade presente em seu método arqueológico, "Longe de ser indiferente à sucessão, a arqueologia demarca vetores temporais de derivação". Ibid., p. 193. Entenda quem puder! 
acontecimentos históricos não revelam nada por si mesmos, qual será a via possível de sua interpretação? Formular à realidade histórica problemas teoricamente adequados, fundando um corpus teórico composto por categorias analíticas capazes de "extrair" significado, a partir da análise de evidências empíricas. E é bom lembrar que a filosofia de Foucault nada tem de idealista, e que ele sempre fez uma defesa convicta do método empírico. Mas, como afirma Patrícia 0'Brien, os historiadores menos dispostos a aceitar sua contribuição para a história apontam "a falta de método, o menosprezo dos dados, a obscuridade filosófica, a linguagem singular, as simplificações excessivas e as abstrações, que para eles refletem a falta de validade histórica da obra de Foucault". ${ }^{18}$

Na via pedregosa e escorregadia da interpretação de textos do passado, o contorno estratégico para viabilizar um processo efetivo de compreensão de um texto deveria passar por um atentado de morte do autor. As figuras aparentemente conhecidas a que denominamos autor e leitor, talvez mereçam uma palavra de definição. Pierre Bourdieu estabelece o contraste, ou melhor, a oposição reconhecida entre estas duas figuras desde a Idade Média: "0 auctor é aquele que produz ele próprio e cuja produção é autorizada pela auctoritas, a de auctor, o filho de suas obras, célebre por suas obras. 0 lector é alguém muito diferente, é alguém cuja produção consiste em falar das obras dos outros". ${ }^{19}$ Entre as duas figuras estará sempre a luta pelo "monopólio da leitura legítima". Definindo o gênero de história das idéias que praticava, ao mesmo tempo em que dissertava sobre 0 seu 'método arqueológico', Michel Foucault observou que "a instância do sujeito criador, enquanto razão de ser de uma obra e princípio de sua unidade, the é estranha. [...] a arqueologia não procura reconstituir o que pôde ser pensado, desejado, visado, experimentado, almejado pelos homens no próprio instante em que proferiram o discurso. [...] Em outras palavras, não tenta repetir o que foi dito, reencontrando-o em sua própria identidade. [...] Não é nada diferente de uma reescrita", ${ }^{20}$

Em sintonia com esta visão, Roger Chartier considera que as leituras são sempre múltiplas, e que são elas que constroem de formas diversas o sentido dos textos, ainda que esses textos expressem de maneira consciente 0 sentido que desejariam ver atribuído a si próprios. ${ }^{21}$ Concepção análoga é expressa por Pierre

${ }^{18}$ O'Brien, P. "A história da cultura de Michel Foucault". In: Hunt, L. (Org.). A nova bistória cultural. São Paulo: Martins Fontes, 1992. p. 41.

19 Bourdieu, P. "A leitura: uma prática cultural. Debate entre Pierre Bourdieu e Roger Chartier". In: CharTier, R. (Org.). Práticas de leitura. São Paulo: Estação Liberdade, 2001. p. 232.

${ }^{20}$ Foucaudr, M. Op. cit. p. 160.

${ }^{21} \mathrm{Cf}$. CharTIER, R. "Aleitura: uma prática cultural. Debate entre Pierre Bourdieu e Roger Chartier". In: CHARTIER, R. (Org.). Op. cit. p. 242. 
Bourdieu, ao afirmar que "nos esquecemos de que um livro muda pelo fato de que não muda enquanto o mundo muda. Quando o livro permanece e o mundo em torno dele muda, o livro muda. [...] Um texto que hoje parece estruturalista amanhã vai parecer durkheimiano, pelo simples fato de que o universo dos compossíveis terá mudado" ${ }^{22}$ Jean-Marie Goulemot ajuda-nos a traduzir este jogo de palavras utilizado por Bourdieu: "Ler é, portanto, constituir e não reconstituir sentido. [...] Quer dizer que cada época constitui seus modelos e seus códigos narrativos e que no interior de cada momento existem códigos diversos, segundo os grupos culturais. Na época de Dom Quixote, Cervantes zombou dos romances de cavalaria que ainda existiam e do público que aceitava seus efeitos de credibilidade e seus códigos narrativos". ${ }^{23}$

Sem a presença incômoda dessa figura opaca, sempre a requerer do intérprete um desafiador "decifra-me ou te devoro", o trabalho de interpretação ficaria livre de uma densa cortina de fumaça. A morte autoral engendrada pelo pós-estruturalismo expressa a idéia de que, no trabalho de exegese de um texto, alcançar o sentido original do discurso em meio à trajetória intelectual e política de homens de carne e osso - ou seja, personagens históricos reais no passado, da mesma forma que nós mesmos no presente, bem como suas intervenções públicas e embates intelectuais -, constitui-se numa tarefa impossível. Isso fundamentalmente porque um texto nunca dirá coisa significativa sobre as intenções particulares de um autor em um momento singular da história. Mas há algo mais. A análise centrada unicamente no texto descobria progressivamente outros fatores de relevância no campo da História das Idéias. 0 teórico da história Paul Veyne declarou as estranhas e surpreendentes implicações do projeto historiográfico levado a cabo por Foucault: "Sinto-me impressionado pelo fato de, nos seus livros, onde aparentemente, apenas há discurso puro e nada mais, onde ele tenta fazer-nos crer que o sexo não existee que é apenas aquilo que se acredita que ele é, se encontrar realmente toda uma História social" . ${ }^{44}$ EJacques Le Goff complementa as impressões de Veyne: "Foucault ensinou aos historiadores, entre outras coisas, que o discurso histórico faz parte da História, mas continua a ser verdade que nós só podemos verdadeiramente considerar Foucault como um historiador se ele entender que o suporte desse discurso não é inapreensível ou inexistente". ${ }^{25} 0$ suporte a que se refere Le Goff, naturalmente, é a própria história efetiva

${ }^{22}$ Bourdieu, P. "A leitura: uma prática cultural. Debate entre Pierre Bourdieu e Roger Chartier". In: CharTier, R. (Org.). Op. cit. p. 250.

${ }^{23}$ Goulemot, J.-M. Da leitura como produção de sentidos. In: Chartier, R. (Org.). Op. cit. pp. 108ss.

${ }^{24}$ VEYNe, P. Texto de entrevista "A História: uma paixão nova", concedida ao Magazine Littéraire e que integra o livro A nova bistória. Lisboa: Edições 70, 1986. (Primeira edição francesa é de 1977). pp. 39.

${ }^{25}$ LE GoFr, J. Ibid.,. pp. 39s. Acerca das similaridades entre Foucault e os historiadores franceses leia-se: Hunt, L "Apresentação". In: —— (Org.). Op. cit. p. 10. 
dos homens. E não parece que a repercussão de Foucault sobre as humanidades em geral tenha gerado os frutos alimentados pela expectativa de Le Goff nos meados dos anos 1970. Como observou alguns anos mais tarde um atento observador da cena historiográfica contemporânea, "Foucault e uma legião de críticos literários tinham dissolvido os fatos em 'discurso', e os historiadores mais na moda, isto é, os identificados com a escola dos Annales [...] tinham dado as costas para a política e os acontecimentos, indo estudar as estruturas e mentalités" ${ }^{26}$ E este mesmo autor complementa: "Como historiador, estou com aqueles que vêem a história como uma construção imaginativa, algo que precisa ser pensado e retrabalhado interminavelmente. (Mas) Não podemos ignorar os fatos nem nos poupar ao trabalho de desenterrá-los, só porque ouvimos falar que tudo é 'discurso"'. ${ }^{27}$

Em sua aula inaugural proferida no Collège de France, em 1970, Michel Foucault procurou escancarar os pontos que se deveria evitar no gênero de História das Idéias: “... (significação, originalidade, unidade, criação) de modo geral dominaram a história tradicional das idéias onde, de comum acordo, se procurava o ponto da criação, a unidade de uma obra, de uma época ou de um tema, a marca da originalidade individual e 0 tesouro indefinido das significações ocultas" ${ }^{28} 0$ programa de trabalho de Foucault exerceu enorme influência sobre os historiadores, e exerce até hoje. E ele próprio conseguiu executá-lo com vigor em trabalhos posteriores como Vigiar e punir e História da sexualidade. ${ }^{29}$ Mas, apesar dos inúmeros elogios normalmente partidos de historiadores franceses, há quem negue veementemente uma alta relevância do pensamento de Foucault, para a história e para as ciências humanas em geral. 0 comentário mais duro vem do historiador italiano Carlo Ginzburg, que o considera "nada mais do que uma nota de rodapé a Nietzsche". ${ }^{30}$

Mas se as intenções autorais eram fragmentos inacessíveis de uma realidade que ficou irremediavelmente perdida no tempo, restavam os suportes formais dos sentimentos, das expectativas e das idéias dos autores - não mais concebidos como mestres do passado, capazes de revelar particularidades de seu próprio tempo e de sua cultura -, mas como os mestres de gerações e gerações de leitores. As interpretações

${ }^{26}$ DarnTon, R. Op. cit. p. 61.

${ }^{27}$ Id., Ibid.,. p. 69 .

${ }^{28}$ Foucauli, M. A ordem do discurso. São Paulo: Loyola, 1999. p. 55.

29 Acerca da reflexão teórica de Foucault, e sua incidência sobre o campo da pesquisa histórica, leia-se os textos de: GrISET, A. "Foucault, um projeto histórico". In: Le Goff, J. et alii. A nova bistória. Lisboa: Edições 70, 1986; O’Brien, P. "A história da cultura de Michel Foucault". In: Hunt, L. (Org.). Op. cit.; Revel, J. "Foucault". In: Burgulìke, A. Dicionário das ciências bistóricas. Rio de Janeiro: Imago, 1993.

${ }^{30}$ GinzBuRg, C. Entrevista. In: Padiares-Burke, M. L. G. (Org.). As muitas faces da bistória. São Paulo: Editora Unesp, 2000. p. 303. 
diversas dessas gerações de leitores eram então um objeto consistente e digno para o trabalho da operação interpretativa. Assim é que, para a análise textualista - ou internalista -, não vinha ao caso analisar Maquiavel, Hobbes ou qualquer outro autor como personagens históricos situados em pontos específicos no tempo, o que poderia incluir as suas motivações, a serem identificadas por meio da leitura atenta de suas criações intelectuais contrastadas com o seu momento e lugar de elaboração. 0 desdobramento da análise textualista leva à desconsideração de qual teria sido o "efeito" que Hobbes tencionou produzir em sua audiência, a partir da circulação de seus textos políticos na Inglaterra dos meados do século XVII. Como se referiu Foucault, "Não é legítimo, pois, indagar à queima-roupa, aos textos que estudamos, sobre seu valor de originalidade [...]. A indagação só pode ter sentido em séries muito exatamente definidas, em conjuntos cujos limites e domínio foram estabelecidos, entre marcos que limitam campos discursivos suficientemente homogêneos". ${ }^{31}$

À leitura pós-estruturalista interessa aquilo que Michel Foucault difundiu, inspirando-se em Montaigne, como a imagem do palimpsesto, as camadas sobrepostas das interpretações acerca dos diferentes sentidos que as gerações sucessivas haviam produzido sobre o pensamento dos autores. Como disse Montaigne, "interpretar as interpretações dá mais trabalho do que interpretar a própria coisa, mas escrevemos mais livros sobre livros do que sobre os assuntos mesmos; comentamo-nos uns aos outros. Há excesso de comentadores mas escassez de autores" ${ }^{32}$ Ao que parece, Foulcault partiu em defesa da multiplicação dos comentadores. Estudando as práticas discursivas no século XVIII, numa perspectiva que combina permanências e rupturas, Michel Foucault observou a sobreposição de valores muito diferentes impregnando a cultura erudita dos homens de letras. Como ele assinalou, "o campo de concomitância da História natural na época de Lineu e de Buffon se define por um certo número de relações com a cosmologia, história da terra, filosofia, teologia, Escrituras Sagradas e exegese bíblica..." "33 Se este 'estiramento' de noções antigas é um dado constatável empiricamente no século XVIII - época em que se acentua o processo de dessacralização da História e da Política e de outras rupturas sensíveis no campo do saber - é de se supor que temas políticos antigos se misturassem aos novos ideais que emergem no século XVII com a chamada crise da consciência européia. Em livro anterior à $A$ arqueologia do saber, Foucault já havia declarado: "uma coisa, em todo o caso, écerta: a arqueologia, dirigindo-se ao espaço geral do saber,

\footnotetext{
${ }^{31}$ Foucault, M. A arqueologia do saber. p. 164.

${ }_{32}$ Montaigne. "Da experiência”. In: — Ensaios. São Paulo: Abril Cultural, 1972. p. 483.

33 Foucault, M. A arqueologia do saber. p. 65.
} 
a suas configurações, e ao modo de ser das coisas que aí aparecem, define sistemas de simultaneidade, assim como a série de mutações necessárias e suficientes para circunscrever o limiar de uma positividade nova". 34

Inequivocamente, no campo teórico da interpretação de textos, estaé uma visada das mais curiosas, e que não deixa de representar interesse para os historiadores, mesmo aqueles que se identifiquem com referências diferentes. De fato, émuito relevante tomar conhecimento do dito palimpsesto, ou seja, daquilo que foi feito de uma obra de pensamento fora do contexto em que se produziu. Chame-se a isto "estética da recepção" ou rotule-se com outras designações também sofisticadas, as reações de leitores constituem uma dimensão muito importante para ser deixada de lado. Tais reações remetem à uma história da leitura, campo disciplinar da História Intelectual que tem demonstrado que tais reações podem desequilibrar a ordem do mundo, ao transformar certos textos em conteúdo programático para a ação política e a pregação doutrinal. Leitores como Lênin e Mao provaram que havia algo mais do que texto no discurso político de Marx. E mesmo que outras leituras não cheguem a tanto, em termos de energia para a transformação de uma dada realidade social, os textos também podem interferir na alteração de uma ordem consolidada em torno de saberes canônicos. A leitura inovadora que Rousseau fez da obra de Maquiavel é um bom exemplo. E não importa tanto diagnosticar leituras defeituosas e sentidos falseados. Ora, numa época de afirmação da idéia republicana era razoável que um filósofo com aíndole de Rousseau enxergasse ideais republicanos aonde quer que olhasse. E ele viu o autor de $O$ Príncipe dando lições à arraia-miúda, para que pudesse se defender contra os caprichos e os desmandos dos donos do poder. E isso na contra-corrente da própria evidência textual de Maquiavel ter se declarado conselheiro dos príncipes, movido por interesses profissionais e pessoais, e por suas convicções cívicas. Então, é relevante saber como os autores foram lidos fora de seu tempo e cultura, e quais foram as diferentes imagens literárias e visões de mundo construídas a partir de suas idéias. Trata-se de um desafio intelectual difícil, e tanto mais ainda quanto mais se alargam os horizontes temporais sob esta perspectiva.

Mas, para o historiador do pensamento político, há um vício que marca essa forma de abordagem dos textos. Este foco lançado sobre a obra de pensamento dissolve a própria essência da história: a noção do tempo histórico e da natureza singular de uma criação intelectual. Focar um texto como se se tratasse realmente do palimpsesto foucaultiano é admitir a sua 'desencarnação' histórica, o seu desenraizamento cultural.

3. Foucuutr, M. As palanras e as coisas. São Paulo: Martins Fontes, 1987. p. 12. 
Hannah Arendt chamava a isso "comércio livre das idéias no tempo", o que de fato parece ser o corolário da interpretação pós-estruturalista, com sua ênfase hipertrofiada na figura do leitor. ${ }^{35}$ Entretanto, o intercâmbio de mentes brilhantes — caso particular de Rousseau e Maquiavel, Lênin/Mao e Marx — não épropriamente uma novidade nos horizontes da hermenêutica e da teoria literária de Ricoeur, de Derrida e de Barthes.

Antes deles, as visadas teóricas de Arthur Lovejoy deram força à interpretação de que os grandes sistemas de idéias formavam uma espécie de circuito filosófico fechado no qual os pensadores retomavam continuamente as idéias de seus predecessores, num autêntico diálogo trans-histórico de tradições intelectuais dispersas em mais ou menos dois mil e quinhentos anos de história. Na perspectiva de Lovejoy, os pensadores políticos de diferentes épocas estiveram engajados numa conversação acerca de temas comuns. Uma tal atitude nas lides da interpretação de textos políticos era algo assim como pretender que, na vida real de cada autor, naturalmente situada num quadro político e social circunscrito no tempo e no espaço, a definição dos temas recorrentes em seus textos quase não tenha sido influenciada por questões contextuais específicas a cada um dos grandes autores da História do Pensamento Político, e sim pela intenção de participar do referido diálogo.

Ora, qual atitude seria mais razoável para se tentar compreender a teoria política hobbesianae, mais particularmente, os aspectos referentes às suas concepções da soberania expressas no Leviatã: enquadrar o tema como fruto de seus diálogos com Aristóteles -e sabemos que Hobbes foi aristotélico até a raiz dos cabelos no período inicial de sua trajetória intelectual -, ou, pelo contrário, ter em mente o fato da influência que sofreu, a partir do estouro da Revolução Inglesa? Imaginar que Hobbes tencionou tão somente participar de um "diálogo" com supostos predecessores acerca da necessidade histórica de uma forma sem partilha do poder soberano ou de qualquer outro tema de teoria política, segundo a interpretação de Lovejoy, implicaria na abolição da história em meio ao processo de exegese de um texto.

Retornando a Barthes e a Derrida, muitas críticas foram dirigidas contra as suas idéias, no plano das teorias de interpretação de textos. 0 foco dos comentários se concentrou no argumento de que, decretando a morte do autor - rebaixado à categoria de um espectro mudo - eles pretenderam converter realidades efetivas em texto. ${ }^{36}$ Tudo seria texto e os sentidos atribuídos aos discursos - extraídos de uma gama variada de suportes

${ }^{35}$ Cf. ARENDT, H. Entre o passado e o futuro. São Paulo: Perspectiva, 1972.

${ }^{36}$ Acerca do tema da morte do autor pode-se ler: Compagnon, A. 0 autor. In: . 0 demônio da teoria: literatura e senso comum. Belo Horizonte: Editora UFMG, 2001. 
- eram quase inteiramente livres, mais ou menos ao sabor das idiossincrasias do sujeito do conhecimento. Para ser mais direto: cada leitor produzirá a sua própria leitura, a partir daquilo que conseguir perceber como a mensagem presente nos textos. A análise do discurso que surge dessa forma de abordagem normalmente é uma leitura intertextual sofisticada, mas freqüentemente a-histórica. Isto porque o círculo hermenêutico não se processa em torno do homem e da obra, numa atitude de remissão à vida efetiva do autor, ao momento da produção de seu texto, que ao fim e ao cabo definem os seus temas. Ao contrário, esses fatores não devem interferir na análise do discurso, que toma como seus 'elementos contextuais' - como o seu chão histórico, por assim dizer -, apenas as "regras de práticas discursivas que atravessam obras individuais" e as diferentes leituras que a tradição crítica fez do texto.

Freqüentemente, quando postas em movimento pelos historiadores, as idéias tendem a ganhar uma energia centrífuga que, em geral, guiam-nas para zonas de escape desprovidas de uma base histórica na qual se apoiar. Interpretações que se atenham apenas ao texto são derrapagens comuns em certo gênero de análise. Esse gênero de interpretação acaba focando suas abordagens em sistematizações teóricas que se esgotam num circuito fechado de idéias, sem que se tente articulá-las com 0 mundo histórico. Este vezo analítico é o que historiadores contextualistas têm denominado por internalismo, com um fraco impulso para a integração do texto ao mundo histórico que o gerou e uma quase total carência de indagações pertinentes à pesquisa histórica. Não se privilegia, por exemplo, o estudo das evidências documentais, ou seja, do testemunho histórico, em relação aos acontecimentos que relata acerca de um dado momento, de um dado horizonte temporal.

Data já de algum tempo o consenso de que a História é um gênero de narrativa, um tipo específico de discurso. Mas um tipo específico de discurso sobre o quê? Ora, sempre houve ou existirá uma realidade fora do texto que requer parcela substancial da atenção dos historiadores. Então, cabe distinguir que se um documento histórico, de qualquer natureza, deve ser apreendido pelo historiador como algo que nunca representa a verdade - é apenas uma representação de realidades contingentes e, portanto, um 'monumento' da capacidade de representação humana - o discurso define algo como a "alma" do texto: uma matéria que apenas tornar-se-á legível pelo esforço da operação interpretativa. Como afirma Ricoeur, o estruturalismo tende a estudar a linguagem poupando o sujeito, a ação, os eventos. ${ }^{37} \mathrm{~A}$ História Intelectual, segundo a defesa que faz dela o contextualismo, investe na capacidade do locutor, na força ilocucionária dos

37 Cf. Ricoeur, P. Em torno ao político. São Paulo: Loyola, 1995. Vol. 01. 
discursos, na capacidade do sujeito em situar-se como ator no mundo, como um agente ativo que se opõe a interlocutores reais, como um coeficiente de força que tenciona atingir um 'alvo' em sua existência histórica concreta.

A presença desses e de outros enfoques no trabalho de interpretação de textos como a hermenêtica de Gadamer, ${ }^{38}$ de Koselleck ${ }^{39}$ e de Ricoeur, ${ }^{40}$ por exemplo -, demonstra como se enriqueceu o aparelhamento teórico disponível à História Intelectual. Gadamer opõe-se à perspectiva de que a compreensão de um texto implique em qualquer tentativa de reconstituição de pensamentos ou intenções originais de uma mens auctoris, como pretendia, por exemplo, o contextualismo de Collingwood. Já Ricoeur argumenta que um discurso, quando passa de uma situação oral para uma condição de texto, perde nesse processo todas as suas implicações dialógicas. 0 dito torna-se algo 'fossilizado' e deixa de pertencer ao horizonte histórico do autor. Para Ricoeur, ao se destacar de seu local de formulação, o texto passa a possuir uma audiência própria eé mais importante decifrar nele o que ele efetivamente diz do que aquilo que ele pretendia dizer. É assim que ele se abre inteiramente a qualquer intérprete, nos limites de sua possibilidade de construir sentidos. Dessa forma, não se poderá reconhecer no texto quaisquer intenções externadas pela referida mens auctoris.

Se esta riqueza gera efeitos muito positivos, também acarreta implicações como a dificuldade do pesquisador discernir quais recursos teóricos são adequados a este ou aquele gênero de pesquisa. Mas, uma evidência salta aos olhos: a de que a História Intelectual, sendo composta por múltiplos interesses ediferentes enquadramentos teóricos, não está mais unificada por grandes conceitos e amplas problemáticas que a reduzam a um gênero único emonocórdio. Como observou Michel Foucault, "não éfácil caracterizar uma disciplina como a história das idéias: objeto incerto, fronteiras mal desenhadas, métodos tomados de empréstimo aqui e ali, procedimento sem retitude e sem fixidez". ${ }^{41}$ E nesse ponto, ao que parece cabe a interrogação: História Intelectual ou Historia das Idéias? Difícil definir, até porque, neste domínio, reina uma radical indeterminação de sentido. Como afirma Chartier, "cada historiografia nacional possui suas próprias designações, e em cada uma delas entram em competição noções diferentes que mal se

\footnotetext{
${ }^{38}$ Cf. Gadamer, H.-G. o problema da consciência bistórica. Rio de Janeiro: Editora FGV, 1998; e Verdade e método. Petrópolis: Vozes, 1997. Vol. 01.

${ }^{39}$ Cf. KoseLLeck, R. Le futur passé. Contribution à la sémantique des temps historiques. Paris: EHESS, 1990; e Le règne de la critique. Paris: Minuit, 1979.

${ }^{40}$ Cf. Ricoeur, P. Interpretação e ideologias. Rio de Janeiro, Francisco Alves, 1988; e Teoria da interpretação. Lisboa: Edições 70, 2000.

${ }^{41}$ Foucault, M. A arqueologia do saber. p. 156.
} 
podem distinguir umas das outras. [...] a História Intelectual não éde modo algum uma disciplina, com os seus objetos ou métodos próprios, sendo prova suficiente a variedade dos textos que se enfileiram sob o seu teto". 42

As análises históricas contextualistas e as interpretações oriundas do pósestruturalismo têm se constituído como correntes de oposição, na esfera mais ampla de uma História Intelectual. No plano estritamente teórico, pode-se conceber esse fato como algo positivo: conduz à complexidade e aumenta 0 grau de sofisticação do debate. E é sempre louvável que adversários possam se esforçar para encontrar pontos de contato e elementos de aproximação, se isto de algum modo contribui para 0 avanço da reflexão. Uma zona de confluência entre o contextualismo ênfase no autor - e o pós-estruturalismo - acento sobre o leitor -, poderia resultar num esforço conjunto para perceber não apenas os sentidos originais (Skinner), ou as redes de conexões (Foucault). A referida zona de confluência no processo de interpretação de um texto, de um discurso político, não pode elidir os elementos irreconciliáveis dessas duas formas de análise. De fato, não seria tarefa factível empenhar-se em descobrir as intenções contidas num texto em seu contexto de formulação, o sentido original a ele atribuído em seu lugar de produção, e ainda incluir neste programa de pesquisa as formas de sua articulação com modos semelhantes ou diferentes de racionalidade. E isso porque existem implicações conceituais como, por exemplo, os níveis de intenção autoral e de indeterminação radical de sentido do discurso que, por serem excludentes entre si, simplesmente inviabilizam tal esforço. Certamente, esse seria um conteúdo programático bastante complexo e de sucesso improvável.

Mas, se não devemos desenvolver a pretensão de tentar integrar teorias e métodos divergentes numa mesma abordagem - sob pena de querer conciliar termos incompatíveis -, podemos reconhecer que alguns desses aspectos, concebidos até agora como irreconciliáveis no processo de interpretação de textos, podem atése revelar fecundos nos horizontes de análises complementares. Basta que não esperemos encontrar neles uma experiência de revelação mística. Isto para afirmar que a idéia de uma única escrita da História, a partir de um 'quadro' interpretativo único, é concepção bastante imperfeita nos dias que correm. Freqüentemente, uma teoria interpretativa começa a demonstrar a sua 'energia criadora' naqueles pontos que as correntes rivais revelam falhas. A idéia de um 'coquetel teórico' (Peter Burke) chacoalhado com ingredientes que não se anulemé

"Cilartigr, R. In: Burguilirl, A. Op. cit.pp. 447ss. 
uma concepção flexível e muito apropriada à História das Idéias. E isso porque aquilo que comumente se denomina 'método' de pesquisa em História não é muito mais do que uma reflexão filosófica particular, uma viagem egóica ao cipoal exuberante das teorias. Dito de outra forma, método não é uma receita que possa ser aplicada indistintamente, como se se tratasse de uma técnica posta em curso por meio de procedimentos mecânicos. Se não, quem em seu juízo perfeito poderia se autodenominar um skinneriano puro, ou um foucaultiano ortodoxo? Aliás, nada mais distante de Foucault do que a ortodoxia. Com efeito, o controvertido método de análise do discurso de Foucault, cujas virtudes foram tão exaltadas - por ele mesmo e por uma legião de entusiasmados seguidores - é um ótimo programa para a pesquisa em História das Idéias. Para gênios, bem entendido. Ora, reconstituir um sistema geral de pensamento como rede integrada, para a qual convergem opiniões compatíveis e contraditórias numa mesma unidade explícita de tempo, eis aí um programa de trabalho fabuloso. Em As palarras e as coisas ele confessou que não era tarefa nada fácil estabelecer o estatuto das descontinuidades para a história tout court. Muito complexa também seria a tarefa de estabelecer o estatuto das descontinuidades para a história do pensamento. A sua perplexidade foi expressa nos seguintes termos: "Como pode um pensamento esquivar-se diante de outra coisa que ele próprio? Que quer dizer, de um modo geral: não mais poder pensar um pensamento? E inaugurar um pensamento novo?" ${ }^{43}$ Então, parece ser verdade que alguns jogos foram pensados para uma só pessoa.

Para concluir, pode-se recordar de algo que, ao menos há umas três décadas, se afigura como um autêntico segredo de polichinelo nas ciências humanas: as teorias estão cada vez mais distantes do dia em que formarão corpus constituído por certezas inabaláveis. Parafraseando Foucault, por trás da fachada visível das sistematizações, é preferível apostar na rica incerteza de uma anarquia ordenada.

\footnotetext{
${ }^{43}$ Foucault. As palavras e as coisas. p. 65.
} 